\title{
Teaching Design and Innovation of the Simulation Training in Management of Enterprises
}

\author{
Zhanzhen ZHANG \\ Qingdao University of Science \& Technology, College of economics and management, Qingdao, China
}

\begin{abstract}
This paper will organically integrate four aspects: interdisciplinary teaching content, teaching methods, teaching mode, teaching technique from a comprehensive point of view. The teaching content is comprised of the establishment enterprises, strategic management, budget management and operation management; the teaching method will include inspiring students with rhetorical questions, role-playing, group discussion, giving reports and many other diverse ways; mutual teaching pattern can be used in the practice teaching; computer technology, simulation software, simulated market environment and enterprise management will be fully exploited in teaching techniques. It is shown that comprehensive simulated experimental teaching of business management plays an influential role in stimulating the subject consciousness and sense of participation in students, broadening economic and managerial students' scope of knowledge, combining the implication of knowledge from respective subjects, training systematic thinking abilities and inspiring innovative entrepreneur spirits.
\end{abstract}

KEYWORD: comprehensive training; teaching design; diversified teaching; teaching of innovation

\section{INSTRUCTIONS}

Various majors of economic management have very strong practicality, so it is important to combination of theory with practice. Strengthening practice teaching is an inevitable requirement of perfecting the teaching system of economic management, cultivating the students' learning ability, practical ability, innovation ability and comprehensive quality. At present, off-campus practice base of the majors of economic management is weak, most enterprises don't want to accept the student internship. Some enterprises accept some students to practice responsibility, but they don't allow them to contact with the core business to avoid leak trade secrets. The comprehensive practical abilities of students' are severely restricted. In order to solve the problems, universities began to explore the school comprehensive experiment (training) to break through the plight of talent cultivation, The Comprehensive Simulation Training in Management of Enterprises can achieve this goal.

\section{COURSE ORIENTATION}

The course is interdisciplinary comprehensive practice course of economic management, it can overcome lack of various professional off-campus practice teaching, improve the students' practice abilities and innovation abilities. It is a teaching mode of experiencing teaching [1], it can simulate the status of the enterprise by the intuitive sand table, the students can experience the whole process of the operation of enterprises including the analysis of the market, generating strategies, organizing production, marketing and financial account .This practical course can integrate the scattered fragments of the majors and the subject knowledge, the students can feel the intrinsic logic relation of different disciplines and different majors, realize the purpose to train interdisciplinary knowledge. This course will cultivate students' comprehensive management abilities and innovative talents.

\section{THE COURSE DESIGN AND INNOVATION}

\subsection{The teaching content design}

Generally, enterprises' development will go through initial, growth period, crisis, transition period, terminal decline, until the collapse of the entire process. In the different stages of enterprises' development, management team of the enterprises need to change the strategies, resource integration, production and marketing management, financial 
management, human resources management and other aspects of business according to their own resources condition and the changing external environment. The contents of The Comprehensive Simulation Training in Management of Enterprises are set up according to the demand of management abilities in the enterprises, it trains the students' comprehensive abilities of applying the knowledge of different disciplines in the actual operating environment, can improve the students' combat level of management.

The course integrates the enterprises' whole process from the enterprise establishment, strategy management, comprehensive budget management, enterprise production and management. It includes eight modules, namely: the enterprise establishment, strategy formulation, comprehensive budgeting, marketing management, production management, human resources management, financial management and enterprise operation simulation.[2]

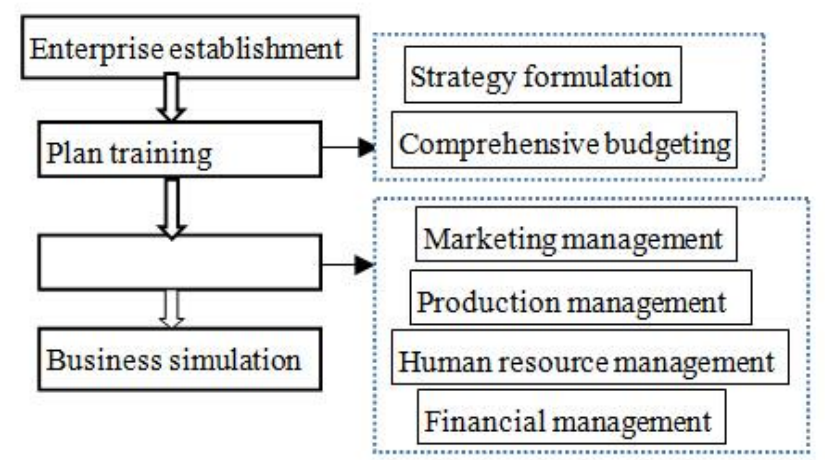

Figure1. The content of The Comprehensive Simulation Training in Management of Enterprise.

\subsubsection{Enterprise establishment}

The training content includes preparations before establishment, the approval of the enterprise's name, opening enterprise's capital verification account, handling the capital verification report and obtaining business licenses, engraved seal and the financial chapter, transacting business organization code certificate, applying tax registration certificate, opening a basic deposit account, setting up enterprise's account, issuing a capital contribution certificate to shareholders, making the management system of the enterprise.

\subsubsection{Strategic management and comprehensive budgeting}

According to its own resources and the external environment, the enterprise analyses and identifies potential opportunities in the market to formulate a correct development strategy. Under the guidance of strategy, the enterprise should set up the annual work plan and make annual budgeting, including sales budget, production budget, procurement budget, direct labor, manufacturing cost budget, production cost, sales cost budget, administration costs budget, financial budget. The establishment should prepare budget income statement, balance sheet budget and cash flow budget based on above budget.

\subsubsection{The enterprise production and management}

Each department carries out the relevant business work in turn according to the established flow and operating budget. Using the sand table in Management of Enterprise, the enterprise carries out a series of activities including sales, production, procurement, warehousing, financial, etc. and completes the various forms. In simulation software environment, the enterprise completes the production and business operation and inspect all kinds of budgets, production and management decision and management performance.

\subsection{The teaching method design}

The course is interdisciplinary and cross different major, its teaching is difficult .According to the different teaching links, different teaching techniques and methods should be adopted in the process of practice.

\subsubsection{The core knowledge review}

We mainly use teaching methods such as inspiring students with rhetorical questions, question type to wake up the related knowledge so as to guide them to apply what they have learned knowledge. In this way, we can achieve the purpose of combining theory with practice.

\subsubsection{The background, the rules of interpretation}

The teaching method, analogy analysis method are used in explaining the training process, new knowledge spot and the difficult points of knowledge. These methods can speed up the student's understanding of relevant knowledge and technique flow.

\subsubsection{The teaching method of physical sand table and electronic countermeasures}

Some practice methods are mainly used such as grouping, role-playing, form simulation, software simulation, etc. The students can get the double training by the physical sand table and electronic countermeasures, they can experience deeply the importance of the market analysis and forecast, decision-making, management, coordination ability, tax planning ability, human resource management ability under the premise of market competitive, their comprehensive abilities of theory with practice will improve rapidly.

Manually operation can be operated first, the students will be proficient in the whole process of 
enterprise operation through personal experience. And then, the electronic countermeasures can be carried on, it can improve operational efficiency. After 6 to 7 years of operation, the students will experience the enterprise' whole operating process, share their business performance visually, they also can find out the advantages and disadvantages in their operations.

\subsubsection{The method of teaching performance report- ing}

The open interactive teaching methods mainly are used such as giving reports, group discussion, etc. After the practice, each enterprise should report its business situation on-site, instructors and rival can ask some questions about their mistakes, shortcomings and the insufficiency, the responsible person should answer the questions. In the process of training, the teacher acts as the director, the students act as actor, this teaching method fully embody the subjectivity of students and the leading of teachers. [3]

\subsection{Teaching mode innovation}

The course involves the different disciplines and specialties including management, marketing, finance, logistics, information, etc., it requirements of high comprehensive quality of the teachers. In the teaching process, the teacher acts as a series of roles: transfer commentator, observers, guide, analysis, business consultant, and so on. To qualify the teaching of ERP simulation experience, teachers need to learn some related discipline knowledge, make full preparations before class.

To ensure the teaching quality of practical training, college should selected some teachers from the professional teaching to prepare the lesson together, they can exchange of experience of different modules so as to improve the overall level of teaching. Mutual teaching pattern can be used in the practice teaching. The different professional teachers are in charge of teaching module, they can be mining knowledge point to deepen the knowledge and professional skills of the module. Diversification of teachers' structure can greatly enhance the teaching quality of practical training.

\subsection{Teaching method innovation}

The physical sand table takes up for a long time, but the students can really feel of enterprise's operators, face the brutal competition in the market, they can learn how to bear the risk of operation and responsibility. In the process, the students can understand the key points of enterprise management, understand how to solve the problem in operations by ERP. Electronic countermeasures simulation can shorten the teaching time and save faculty, but some students may not realize application knowledge, their experiences are not deep enough. Teachers should lead the students pay special attention to the use of auxiliary teaching system.

The aim of the auxiliary teaching system is to solve the problems in practical training with information technology and electronic way, it is an important innovation of teaching methods which can improve students' learning efficiency. The system has the following advantages:

\subsubsection{Humanistic online help system}

Some universal problems appeared in past practice are summarized and displayed the detailed answer with text, video in the Web page one by one. The teacher will mainly answer individual problems which appear randomly in the training, then his answer can be recorded timely and input in the online help system, the difficult problems of knowledge online help system will be constantly improved.

\subsubsection{The stronger man-machine interaction}

In teaching of the electronic practical training, every step of the students or teachers must be complete according to the programming step, so the next step can be continued. In this way the fairness of combat simulation can be ensured

\subsubsection{Intelligent systems}

The system has the visual, interface and function of automatically generate financial statements, the enterprise can find out the current operations and financial conditions by clicking the icon view at any time. At the same time, the enterprises' information can be shown by multiple views, it brings most convenience to the enterprises, they can query, gather and analyze information from different angles to help managers to make correct decisions.

\subsubsection{Reliability}

The system uses a large database transaction processing mechanism, the consistency of the data can be ensured, so the operating system is safe and reliable. System maintenance and improvement needs the assistant of the computer management professionals, teachers need to work closely with them[4].

\section{TEACHING PRACTICE EFFECT}

We investigated the training effect before the end of each round. We completed the survey by random sampling method and the questionnaire survey, the questionnaire included course content design, the organization forms, teaching methods, etc., we 
distributed 200 questionnaires, withdraw questionnaire 194, the recovery rate of $97 \%$.

Students' satisfaction of the course content was $92.5 \%$, the satisfaction to the form of teaching organization was 95\%, students' satisfaction of training guidance method was $94.5 \%$, students' satisfaction on training effect was $91 \%$.

Investigation shows: in the course of investigation to improve the practice ability, $90 \%$ of the students think very satisfied, $8 \%$ of the students think that the satisfaction, only $2 \%$ of the students think that the fair or not satisfied; To improve the inter professional learning and application ability, $85 \%$ of the students think very satisfied, $10 \%$ of the students think that the satisfaction, $5 \%$ of the students think that the fair or not satisfied; In the course of enterprise management and improve their abilities, $91 \%$ of the students think very satisfied, $6 \%$ of the students think that the satisfaction, $3 \%$ of the students think that the fair or not satisfied; In the course of employment and work in the future, $86 \%$ of the students think very satisfied, $9 \%$ of the students think that the satisfaction, $5 \%$ of the students think that the fair or not satisfied.

In past few years, the comprehensive training effect display students have a clear understanding of the enterprise from the establishment, plan management, business management, etc. Their abilities of applying interdisciplinary knowledge improved obviously. Their abilities of integrating theory with practice, the sense of teamwork and their comprehensive quality improved obviously, students' employment ability is strengthen.

\section{RESEARCH CONCLUSION}

The comprehensive simulated experimental teaching of business management plays an influential role in stimulating the subject consciousness and sense of participation in students, broadening economic and managerial students' scope of knowledge, combining the implication of knowledge from respective subjects, training systematic thinking abilities and inspiring innovative entrepreneur spirits.

But in a realistic environment, the enterprise will face complex management environment, changing management pattern, multifarious business categories, many business are unable to simulate. The content of the practical training course is relatively simple, the practice rules are single. The content of the practical training system need to be further perfected, teaching method and the technology also need to be further improved,

\section{REFERENCES}

[1] Xiang-you Lin, Xia Cheng, Ting-min Ceng.2008. Perfecting of teaching in ERP simulation experience .Finance and accounting monthly, 4:89-90.

[2] Jie Huang, Xue-min Zhang, Qinghua Yan. 2012. Practical Training of Business Operation and management. Chengdu: Southwestern University of Finance and Economics press, $1-1$

[3] Xuemin Zhang. 2013. Interdisciplinary Comprehensive Training Innovation of the Economic and Managerial Majors Under the Framework of TPACK - With the Example of the Teaching Design and Practice in the Comprehensive Simulation Training in Operating Decision and Management of Enterprises. The Modern education Technology, 23(3):114-117

[4] Wang Guanzhong. 2010. Teaching method innovation of ERP sand table training applied undergraduate talents training in economics and management. Forest District Teaching, 161:6-7 